\title{
Anti-retinal antibodies in patients with macular telangiectasia type 2
}

Zhu, L ; Shen, W ; Zhu, M ; Coorey, N J ; Nguyen, A P ; Barthelmes, D ; Gillies, M C

DOI: https://doi.org/10.1167/iovs.13-12050

Posted at the Zurich Open Repository and Archive, University of Zurich

ZORA URL: https://doi.org/10.5167/uzh-85758

Journal Article

Accepted Version

Originally published at:

Zhu, L; Shen, W; Zhu, M; Coorey, N J; Nguyen, A P; Barthelmes, D; Gillies, M C (2013). Anti-retinal antibodies in patients with macular telangiectasia type 2. Investigative Ophthalmology Visual Science [IOVS], 21(54):5675-5683.

DOI: https://doi.org/10.1167/iovs.13-12050 


\section{Anti-retinal antibodies in patients with Macular Telangiectasia Type 2}

Ling Zhu ${ }^{1}$, Weiyong Shen ${ }^{1}$, Meidong Zhu ${ }^{1,2}$, Nathan J. Coorey ${ }^{1}$, An P. Nguyen ${ }^{1}$, Daniel Barthelmes $^{1}$, Mark C. Gillies ${ }^{1}$

1. Save Sight Institute, the University of Sydney, Sydney 2000, Australia

2. Lions NSW Eye Bank, NSW Organ and Tissue Donation Service, South Eastern Sydney Local Health District, Sydney, Australia

Correspondence should be addressed to:

Ling Zhu, PhD

Save Sight Institute

The University of Sydney

8 Macquarie Street, Sydney 2000, Australia

Tel: 61-2-9382 7270

Fax: 61-2-9382 7318

E-mail: ling.zhu@sydney.edu.au

This study was supported by a grant from Lowy Medical Research Institute (Australia). Mark Gillies is a fellow of Sydney Medical School Foundation and is supported by a National Health and Medical Research Council (Australia) Practitioner Fellowship. 
Purpose: Macular Telangiectasia Type 2 (MacTel-2) is a retinal disease that can cause loss of central vision. To gain better understanding of the aetiology and pathogenesis of the MacTel-2, we investigated antigens which prompt the generation of retinal autoantibodies in the sera of MacTel-2 patients.

Methods: We screened for the presence of retinal autoantibodies in 45 sera collected from MacTel2 patients and 68 sera from healthy controls by Western Blot. We then isolated and identified three retinal proteins which are putative targets of three most frequently detected autoantibodies in the sera of MacTel-2 patients, using chromatographic fractionation and Liquid chromatography-tandem mass spectrometry (LC-MS/MS). We also validated the retinal location of the three antigens by immunohistochemisty using both MacTel-2 sera as primary antibodies, as well as commercial antibodies.

Results: Retinal autoantibodies were detected in a significantly higher proportion of MacTel-2 patients than in healthy controls $(31 / 45$ [69\%] vs. 9/58 [16\%], $\mathrm{P}<0.0001)$. The three antigens that were targeted by the most frequently detected MacTel-2 autoantibodies were identified as Glycogen debranching enzyme (AGL), Retinol-binding protein 3 (RBP3) and Creatine kinase type-B (CK-B). Autoantibodies against above antigens were found in 4, 11 and 9 MacTel-2 sera respectively.

Conclusions: We found that most MacTel-2 patients possess retinal autoantibodies, the most prevalent of which were directed against AGL, RBP3 and CK-B. The localisation of retinal proteins bound by AGL, BRP3 and CK-B autoantibodies is consistent with their putative physiological functions. These findings provide potentially novel mechanisms for the aetiology and pathogenesis of MacTel-2. 


\section{Introduction}

The retina is thought to be an 'immune-privileged' site, which allows it to tolerate the introduction of antigens without eliciting an inflammatory immune response. This may protect the retina from inflammatory damage which would have potentially disastrous consequences for vision, since the retina has very limited regenerative capacity ${ }^{1}$.

The blood-retinal barrier (BRB) is the interface between systemic circulation and the retina. It consists of non-fenestrated capillaries of the retinal circulation with tight-junctions between retinal vascular endothelial and retinal pigment epithelial cells. The BRB's ability to prevent free entry and exit of cells and larger molecules into and out of the retina is critical for the maintenance of immune-privilege. Breakdown of the BRB is an important feature of many retinal diseases, including Macular Telangiectasia Type 2 (MacTel-2), Age-Related Macular Degeneration (AMD), and Diabetic Retinopathy (DR) ${ }^{2-4}$. Breakdown of the BRB exposes retinal antigens to the immune system, eliciting an inflammatory response which can cause tissue damage and vision loss ${ }^{5}$. Autoantibodies against retinal antigens have been detected from a number of ocular disorders including autoimmune retinopathy ${ }^{6,7}$ and AMD ${ }^{8-10}$.

MacTel-2 is a potentially blinding condition of the retina, yet its aetiology and pathological mechanisms remain poorly understood ${ }^{4}$. Although it has been reported that MacTel-2 is present in $0.1 \%$ of the population above 43 years of age, the actual prevalence may be higher ${ }^{4,11}$. MacTel-2 affects both eyes with a predilection for the temporal parafovea ${ }^{12}$. Leak is seen on fluorescein angiography but cystic oedema is usually absent. Biomicroscopic features of MacTel-2 include right angle vessels and deep retinal neovascularisation, loss of macular transparency, superficial white crystals, inner retinal cavitation without retinal thickening, foveal thinning and photoreceptor atrophy.

In order to explore this retinal disease further, retinal autoantibodies were profiled in sera of MacTel-2 patients and the results were compared with that obtained from healthy controls. We first screened for the presence of autoantibodies in sera of MacTel-2 patients and then isolated the target 
antigens through chromatography, which were subsequently subjected to Liquid chromatographytandem mass spectrometry (LC-MS/MS) for protein identification. We then performed immunohistochemical studies on human retinae using MacTel-2 sera as primary antibodies to identify the retinal cell types that were bound by the target autoantibodies. These results were further validated using commercially available antibodies.

\section{Material and methods}

\section{Patient information and serum collection}

The study was approved by the Human Research Ethics Committee of the South Eastern Sydney Local Health District - Northern Sector, NSW, Australia. Written informed consent was obtained from all participants who donated serum. This research adhered to the tenets of the Declaration of Helsinki.

Peripheral blood samples were collected from participants in The Natural History Observation Study of MacTel-2 (NHO MacTel-2) ${ }^{13}$. The inclusion and exclusion criteria for enrolment in the NHO MacTel-2 were a clinical diagnosis of bilateral MacTel-2, who did not have DR or were afflicted with only background DR (less than ten microaneurysms without retinal haemorrhage) but without other confounding ocular conditions that may have prevented the evaluation of the condition (Table 1).

The final diagnosis of MacTel-2 was confirmed by the Moorfields Reading Centre at Moorfields Eye Hospital, London, UK on the basis of colour fundus photographs, optical coherence tomography (OCT) scans, fundus fluorescein angiography, fundus autofluorescence, blue light reflectance and microperimetry. The diagnosis was confirmed in all cases by attenuation of central masking of background autofluorescence by luteal pigment with other signs, including temporal parafoveal telangiectasis with late staining seen on fluorescein angiography, superficial white crystals, foveal thinning, inner retinal cavitation and photoreceptor disruption seen on OCT. Breakdown of the blood-retinal barrier was graded by an experienced retinal clinician (MG) on the 
extent of leakage during angiography 5 minute after fluorescein injection as absent, mild, moderate or severe

For healthy controls, blood samples were collected from a group of people who were enrolled into the NHO MacTel-2 study as blood relatives or non-blood related controls of MacTel-2 patients. The Moorfields Reading Centre confirmed that they had neither MacTel-2 nor other retinal diseases based on their clinical signs and the ocular images.

\section{Retina tissue processing}

Five post-mortem human (age from 62-75) retinae were obtained from the Lions NSW Eye Bank, Sydney, Australia following the Australian Therapeutic Goods Administration (TGA) guidelines for the use of human tissues for research. The ethics approval for the use of post-mortem human tissues for this project was obtained from the University of Sydney Ethics Committee, Sydney, Australia.

Human retinae were homogenized in RIPA buffer with protease inhibitor complex (Roche, Australia). The homogenates were constantly shaken for 30 minutes $\left(4^{\circ} \mathrm{C}, 60 \mathrm{rpm}\right)$ then centrifuged

at $12000 \mathrm{~g}$ for 30 minutes at $4^{\circ} \mathrm{C}$. Supernatants were collected, pooled and stored at $-80^{\circ} \mathrm{C}$ until use. Protein concentration was determined using BCA protein assay (Sigma, Australia). Total retinal protein homogenates were mixed with NuPAGE loading dye (4x) and reducing buffer (10x) (Invitrogen, Australia), then heated for 10 minutes at $70^{\circ} \mathrm{C}$. The supernatant was collected after centrifugation at $12000 \mathrm{~g}$ for 5 minutes.

\section{Autoantibody screening}

Approximately $1 \mu \mathrm{g}$ of protein was loaded per $1 \mathrm{~mm}$ of the NuPAGE Tris-Bis gel (Invitrogen, Australia). The precast gels were manually modified to include a single small well for loading the protein standard and a large "prep" well ( $6.5 \mathrm{~mm}$ length) allowing the total retinal protein sample to be applied across the whole gel. Proteins were separated by electrophoresis at constant $180 \mathrm{~V}$ at $4^{\circ}$ $\mathrm{C}$ for 1 hour. The gels were transferred onto PVDF membrane (Millipore, Australia) at constant $100 \mathrm{~V}$ at $4^{\circ} \mathrm{C}$ for 1 hour. 
The PVDF membranes were incubated in 5\% BSA, 0.1\% tween, TBST for 1 hour at room temperature to block non-specific binding. Serum from each participant was diluted $(1: 200)$ and reacted with the membrane overnight at room temperature. A multiscreen apparatus (Bio-Rad, Australia) allowed the large area of blotted protein to be divided into individual chambers, therefore a single blot could be used to test sera from up to 18 individuals. Each chamber had a total volume of $600 \mu \mathrm{L}$.

After overnight incubation in sera, membranes were washed in $0.1 \%$ TBST three times then incubated with goat anti-human IgGAM (1:10000, Invitrogen, Australia) at room temperature for $1 \mathrm{~h}$. This polyclonal antibody recognizes both heavy and light chains of human IgG, IgA and IgM. After three washes in $0.1 \%$ TBST, the blot was incubated in ECL Western Blotting (WB) detection reagent (Millipore, Australia) for 5 minutes and photographed using the G-Box imaging system (In Vitro Technologies, Australia).

\section{Chromatography Fraction}

Total human retinal protein was extracted by RIPA buffer as described above. The dialysis was performed in Buffer A (50 mM Tris Ph 8.0), and then loaded into an iron exchange column (HiTrap Q HP, $1 \mathrm{ml}$, GE Healthcare, Australia). Proteins were eluted out based on their different surface charges. Different elution fractions of $0 \%, 10 \%, 20 \%, 30 \%, 40 \%, 50 \%, 60 \%, 70 \%, 80 \%, 90 \%$ and $100 \%$ of Buffer $\mathrm{B}(1 \mathrm{M} \mathrm{NaCl}, 50 \mathrm{mM}$ Tris Buffer $\mathrm{Ph} 8.0)$ were collected and subjected to WB for tracking the antigen, in which sera from MacTel-2 patients were used as primary antibodies.

The antigen-containing fraction was further dialyzed into $1 \mathrm{M}$ Ammonium sulfate and 50 $\mathrm{mM}$ potassium phosphate buffer $\mathrm{Ph} 7.5$, then loaded onto a Hydrophobic Interaction Chromatography Column (HiTrap Butyl HP, GE healthcare, Australia). Proteins were eluted out based on their different hydrophobicity. Different elution fractions were collected and subject to WB to track the antigens as described above.

The antigen-containing fractions were dialyzed to exclude the salt and then concentrated. Fractions were run in parallel on two identical 4-12\% NuPAGE Tris-Bis gels (Invitrogen, Australia) 
at a constant $180 \mathrm{~W}$ for 1 hour. The first gel was processed for WB using MacTel-2 sera to identify the exact position of the target antigen. Protein bands were stained in the second gel with SimplyBlue SafeStain (Invitrogen, Australia). The desired antigen-containing bands in the second gel were identified using the corresponding migration distance of the target proteins in the membrane subjected to WB. The antigen-containing bands in the second gel were excised, destained and dried before being digested overnight using trypsin (Promega, Australia). Digests were extracted using $60 \%$ acetonitrile $(\mathrm{ACN}) / 0.1 \%$ trifluoroacetic acid. The extracts were dried with a speed vacuum and reconstituted in 5\% ACN/0.1\% formic acid and applied to reverse phase NanoLC mass spectrometry (Australian Proteome Analysis Facility, APAF).

\section{Tandem mass spectrometry data acquisition}

The digests were dissolved in $40 \mu \mathrm{L}$ of ESI loading buffer, injected onto a peptide trap (Michrome peptide Captrap) for pre-concentration and desalted with $0.1 \%$ formic acid, $2 \% \mathrm{ACN}$, at $8 \mu \mathrm{L} / \mathrm{min}$. The peptide trap was switched in line with the analytical column. Peptides were eluted from the column, using a linear solvent gradient, stepwise from $\mathrm{H}_{2} \mathrm{O}: \mathrm{CH}_{3} \mathrm{CN}(100: 0,+0.1 \%$ formic acid) to $\mathrm{H}_{2} \mathrm{O}: \mathrm{CH}_{3} \mathrm{CN}(10: 90,+0.1 \%$ formic acid) at $500 \mathrm{~nL} / \mathrm{min}$ over $80 \mathrm{~min}$. The LC eluent was analysed with positive ion nanoflow electrospray MS on QSTAR, which was operated in an information dependant acquisition mode (IDA). In IDA mode, a TOF MS survey scan was acquired (m/z 400$1600,0.5 \mathrm{~s}$ ) with the three largest multiply charged ions (counts $>25$ ) sequentially subjected to tandem mass spectrometry analysis. MS/MS spectra were accumulated for $2 \mathrm{~s}(\mathrm{~m} / \mathrm{z}$ 100-1600).

\section{Data processing}

The data were exported and submitted to the database search program, ascot (Matrix Science Ltd, London UK). Peaklists were searched against Homo sapiens in SwissProt database. High scores in the database search indicate a likely match which is confirmed or qualified by operator inspection.

\section{Immunohistochemistry (IHC)}

Two post-mortem human eyes from healthy donors were used for immunohistochemical studies. The approximate time from death of the patient to storage of the globe was 12 hours. After 
removing corneas, eye cups were fixed in $4 \%$ paraformaldehyde for 4 hour followed by equilibration in $20 \%$ sucrose overnight. After dissecting eye cups into smaller pieces, tissues were embedded in Optical Cutting Temperature Compound (ProSciTech, Australia) for cyrosectioning.

In order to identify the types of retinal cells targeted by autoantibodies detected in MacTel-2, cyrosections $(10 \mu \mathrm{m})$ were incubated with 1: 50 dilutions of MacTel-2 sera, overnight at $4{ }^{\circ} \mathrm{C}$. Antibody binding was detected by incubation of sections with goat anti-human IgG $(\mathrm{H}+\mathrm{L})$ conjugated with Alexa Fluor $488\left(1: 1000\right.$, Invitrogen) at $37^{\circ} \mathrm{C}$ for 2 hours. The nuclei were counterstained with $10 \mu \mathrm{g} / \mathrm{ml}$ propidium iodide in PBS for $5 \mathrm{~min}$. The stained sections were examined with a confocal microscope (LSM700, Carl Zeiss).

To validate the results of IHC in which MacTel-2 sera were used as primary antibodies, cyrosections were also incubated with commercial antibodies against proteins revealed by Tandem Mass Spectrometry data acquisition. The commercial antibodies used for further validation included anti-creatine kinase B type (CK-B, Santa Cruz, \#sc-1517); anti-retinol-binding protein 3 (RBP3,Abcam, \#ab101456) and anti-glycogen debranching enzyme (AGL, C-term, Abgent, AP2402b). IHC was performed as described above.

\section{Results}

\section{Retinal autoantibody detection}

Forty-five blood samples were collected from confirmed MacTel-2 patients and 68 samples from healthy controls. To detect autoantibodies present in MacTel-2 sera, we performed WB analysis using sera as primary antibodies to probe the total proteins extracted from human retinae. Various band patterns were detected, especially in membranes blotted with MacTel-2 sera (Figure 1A).

Overall, we detected autoantibodies against human retinal proteins in 68\% (31/45) of MacTel-2 sera, while only $16 \%(9 / 58)$ of healthy controls showed positive bands (Table $1, \mathrm{P}<0.0001)$. Fisher's exact test gave an odds ratio of 12.1, indicating that the likelihood of MacTel-2 patients having retinal autoantibodies is significantly greater than individuals in the healthy control group. 
Three bands were frequently detected in MacTel-2 sera, which did not appear in sera from healthy controls. We named these three unknown proteins antigen $\mathrm{X}(\sim 150 \mathrm{kDa})$, antigen $\mathrm{Y}(\sim 120$ $\mathrm{kDa})$ and antigen $\mathrm{Z}(\sim 40 \mathrm{kDa})$ (Figure 1B). Autoantibodies against antigens $\mathrm{X}, \mathrm{Y}$ and $\mathrm{Z}$ were found in 4, 11 and 9 MacTel-2 sera respectively. In addition, we also detected low MW (less than $40 \mathrm{kDa}$ ) autoantibody band in 7 MacTel-2 sera, but were not detected in multiple patients. Not surprisingly, we also detected $16 \%(9 / 58)$ of healthy control sera containing low MW autoantibody bands when probing against human total retinal proteins. No samples shared a MW similar to $\mathrm{X}, \mathrm{Y}$ or $\mathrm{Z}$. This is consistent with a report identifying a certain percentage [19\% (15/79)] of low MW autoantibodies detected in healthy control sera ${ }^{14}$.

Reviewing the clinical data of all these Mactel-2 patients with autoantibody $\mathrm{X}, \mathrm{Y}$ or $\mathrm{Z}$ revealed that most patients were afflicted with advanced MacTel-2. Two of 11 patients with autoantibody Y were observed to have retinal hyper autofluorescence, which occurs in only around $5 \%$ of the general population with MacTel ${ }^{15}$. Patients in autoantibody $\mathrm{Z}$ groups exhibited more pronounced BRB breakdown than other cases (data not shown).

\section{Antigen fractionation and identification}

To identify the three retinal proteins targeted by the three autoantibodies which were detected in the MacTel-2 sera, chromatography was used to fractionate the human retinal proteins. As described in the methods, we first separated human retinal protein lysates by the surface charge using an ion exchange column ( $\mathrm{Q}$ column) and then chose the fractions containing our target antigens to be further isolated by hydrophobicity using a hydrophobic column (Butyl column). Each isolation step was validated by WB using MacTel-2 sera containing the autoantibody against antigen $\mathrm{X}, \mathrm{Y}$ or $\mathrm{Z}$. (Figure 2A-C, indicated by asterisks). The antigen-containing protein fraction was then run, in parallel, on two identical SDS-PAGE. The first gel was used to identify the exact position of the target antigen by WB using MacTel-2 serum containing target autoantibody. The desired antigencontaining band stained by SimplyBlue in the second gel was identified using the corresponding 
migration distance of the target protein in the membrane subjected to WB. The antigen-containing band in the second gel was excised (Figure 2D-F, asterisks), purified and analysed with LC-MS/MS. As shown in Table 2, the LC-MS/MS analysis revealed antigen X as Glycogen Debranching Enzyme (AGL), a protein related to energy metabolism ${ }^{16}$, antigen $\mathrm{Y}$ as Retinol-Binding Protein 3 (RBP3), which is known to play important roles in the visual light cycle ${ }^{17}$ and antigen $\mathrm{Z}$ as Creatine kinase Brain type (CK-B), which is a factor involved in energy metabolism in the visual cycle $^{18}$. LC-MS/MS analysis detected multiple matching sequences consistent with our predicted target proteins, which confirmed our earlier analysis. See Supplementary material for details of LCMS/MS results for three antigens identification.

\section{Antigen localisation}

IHC was conducted using MacTel-2 sera and commercial antibodies against AGL, RBP3 and CK-B to localize the target cell types in human retinae. (Figures 3 and 4, Table 3). IHC using MacTel-2 serum containing anti-AGL as a primary antibody produced strong immunostaining around retinal blood vessels in the inner retina, along with weak staining in astrocytes and cells in both the inner nuclear layer (INL) and outer nuclear layer (ONL) (Figure 3A-C). IHC using a commercial antiAGL antibody produced a similar immunoreactivity pattern (Figure 4A-C). IHC with MacTel-2 serum containing anti-RBP3 showed that RBP3, a molecule responsible for the transfer of 11-cis retinal and all trans-retinol between the photoreceptors and retinal pigment epithelium (RPE) ${ }^{19}$, was abundantly expressed in the photoreceptor outer segments (Figure 3D-F). This finding was further confirmed by immunostaining using a commercial anti-RBP3 antibody (Figure 4D-F). IHC with MacTel-2 serum containing anti-CK-B showed that CK-B was globally expressed throughout the entire retina and high CK-B expression was observed in the photoreceptor outer segments (Figure 3G-I). Immunostaining using a commercial anti-CK-B antibody revealed similar staining results to those observed with CK-B serum (Figure 4G-I). To further confirm the identity of the Z antigen as CK-B, we blotted patient serum against a recombinant CK-B protein. Sera from all All nine patients were positive for recombinant CK-B protein when compared with health control serum 
(Supplementary Figure 1). There was no obvious immunoreactivity in the human retina when healthy control sera was used as primary antibodies for IHC (Figure 3J-L). Thus these IHC results indicate that MacTel-2 patients can produce autoantibodies to target specific retinal proteins.

\section{Discussion}

This study is the first to report the presence of autoantibodies against retinal proteins in sera from people with MacTel-2. We identified three retinal proteins, including AGL, RBP3 and CK-B, which appear to be the targets for many of these autoantibodies. These data may serve as a foundation for further studies aimed at elucidating the pathogenic mechanisms that cause MacTel-2.

AGL is involved in glycogen metabolism through facilitating glycogen breakdown ${ }^{20}$. Immunohistochemistry revealed AGL was found mainly around inner retinal vessels, with weak expression in astrocytes and cells of both the INL and ONL. It has been reported that glycogen may be used by Muller cells to generate lactate for neighbouring cells ${ }^{21,22}$. Our previous proteomics study determined there is a downregulation of glycolytic pathway proteins in the retina of a patient

afflicted with MacTel-2 ${ }^{23}$. The glycolytic pathway is dominant in glial cells, including astrocytes in the superficial retina and Muller cells which span the full thickness of the neural retina. Compromise of this pathway may affect the energy supply of photoreceptors. This might be exacerbated by the presence of AGL autoantibodies in MacTel-2 patients. Autoantibodies against AGL have not been reported for any other retinal disease. Whether anti-AGL autoantibody could be used as a biomarker, unique to MacTel-2, warrants further investigation.

RBP3 is essential for the exchange of retinoid between the RPE and photoreceptors. The presence of sufficient quantities of functional RBP3 is also critical to photoreceptor survival since it serves to prevent the potentially cytotoxic effects of retinoids. We detected RBP3 autoantibody in around 25\% (11/45) of MacTel-2 patients and our IHC studies found these autoantibodies bound photoreceptor outer segments strongly. Intriguingly, also found RBP3 autoantibody in 33.3\% (6 out 
of 18) of AMD patients' sera (unpublished data). Detection of a common autoantibody might indicate that both MacTel-2 and AMD share some common aetiologic or pathogenic mechanisms.

It is possible that RBP3 autoantibodies could contribute to outer retinal degeneration. Reduced levels of functional RBP3 protein in the interphotoreceptor matrix might interfere with the visual cycle that represents the natural exchange of proteins between the photoreceptors and RPE. This disruption could result in the accumulation of all-trans retinol, which is readily transformed through condensation to N-retinylidene-N-retinylethanolamine (A2E) ${ }^{24}$, a prominent component of the retinal 'waste product' lipofuscin. A2E is also known to be responsible for retinal autofluorescence, a phenomenon that is a standard AMD diagnostic marker ${ }^{25,26}$. Increased autofluorescence due to accumulation of subretinal debris has also been observed in a small proportion MacTel-2 patients ${ }^{15,27}$.

CK-B is an important enzyme for vertebrate energy metabolism ${ }^{18}$. It catalyses the conversion of creatine, consuming adenosine triphosphate (ATP), phosphocreatine and adenosine diphosphate (ADP), in the visual cycle ${ }^{18}$. CK-B is critical for providing energy for the visual cycle in photoreceptors. CK-B autoantibody has been detected in $25 \%$ of people with Vogt-KoyanagiHarada disease and $38 \%$ of those with sarcoidosis ${ }^{28}$, prevalences which are similar to the $20 \%$ (9/45) that we found in people with MacTel-2. Interestingly, sera from patients with DR, paraneoplastic sensory-dominant neuropathy and non-paraneoplastic autoimmune retinopathy has also been reported to contain autoantibodies binding to CK-B ${ }^{29-31}$. We found CK-B antibodies globally expressed throughout the retina, with a particularly high expression in photoreceptor outer segments. Since CK-B is abundantly expressed in the retina ${ }^{18}$, the presence of CK-B antibody in MacTel-2 patients may adversely affect their visual function. After reviewing the clinical data of all 9 patients whose sera contained CK-B antibody, we found all these patients exhibitedmore pronounced BRB breakdown, determined angiographically, than individuals from the set of people with MacTel-2. This suggests that the presence of CK-B autoantibody in these patients may 
contribute to retinal vasculopathy and may have clinical significance for the early diagnosis of retinal vascular diseases such as MacTel-2 and DR.

A potential mechanism underlying the generation of retinal autoantibodies is the activation of microglia by the stressed retina. Activated microglia may phagocytose target retinal antigens and then enter the systemic circulation where they may become antigen presenting cells ${ }^{32}$. This could result in a vicious circle, whereby more autoantibodies pass the compromised BRB leading to an increase of phargocytosed antigens. This would not only impair the function of these antigens, but also damage surrounding areas due to inflammation.

MacTel-2 remains poorly understood, both aetiologically and pathologically. The presence of different autoantibodies in people with MacTel-2 suggests that the clinical picture might be produced by different pathogenic processes. For instance, autoantibodies against AGL may contribute to impairment of the glycolytic pathway. RBP3 autoantibodies might contribute to photoreceptor damage since most of MacTel-2 patients with this autoantibody were at a more advanced pathogenic stage. CK-B autoantibody was detected in MacTel-2 patients with more pronounced vasculopathy. Clinically there is great variation in the degree of neuronal or vascular damage from one patient to another. Further studies on the relationship between different autoantibodies,clinical phenotypes and progression rates are warranted.

In summary, we found that most MacTel-2 patients possess retinal autoantibodies, the most prevalent of which were directed against AGL, RBP3 and CK-B. The localization of retinal proteins bound by AGL, BRP3 and CK-B autoantibodies was consistent with their putative physiological functions. These findings provide potentially novel mechanisms for the aetiology and pathogenesis of MacTel-2. Further studies will be required to determine whether these autoantibodies have a causative role in photoreceptor damage and BRB breakdown or whether they are simply a secondary phenomenon which is a non-specific reaction to retinal disease. 


\section{Reference}

1. Streilein JW. Ocular immune privilege: therapeutic opportunities from an experiment of nature. Nature reviews Immunology 2003;3:879-889.

2. Jager RD, Mieler WF, Miller JW. Age-related macular degeneration. The New England journal of medicine 2008;358:2606-2617.

3. Gardner TW, Antonetti DA, Barber AJ, LaNoue KF, Levison SW. Diabetic retinopathy: more than meets the eye. Survey of ophthalmology 2002;47 Suppl 2:S253-262.

4. Coorey NJ, Shen W, Chung SH, Zhu L, Gillies MC. The role of glia in retinal vascular disease. Clinical \& experimental optometry : journal of the Australian Optometrical Association 2012;95:266-281.

5. Caspi RR. Ocular autoimmunity: the price of privilege? Immunological reviews 2006;213:23-35.

6. Adamus G. Autoantibody targets and their cancer relationship in the pathogenicity of paraneoplastic retinopathy. Autoimmunity reviews 2009;8:410-414.

7. Heckenlively JR, Ferreyra HA. Autoimmune retinopathy: a review and summary. Seminars in immunopathology 2008;30:127-134.

8. Patel N, Ohbayashi M, Nugent AK, et al. Circulating anti-retinal antibodies as immune markers in age-related macular degeneration. Immunology 2005;115:422-430.

9. Joachim SC, Bruns K, Lackner KJ, Pfeiffer N, Grus FH. Analysis of IgG antibody patterns against retinal antigens and antibodies to alpha-crystallin, GFAP, and alpha-enolase in sera of patients with "wet" age-related macular degeneration. Graefe's archive for clinical and experimental ophthalmology = Albrecht von Graefes Archiv fur klinische und experimentelle Ophthalmologie 2007;245:619-626.

10. Cherepanoff S, Mitchell P, Wang JJ, Gillies MC. Retinal autoantibody profile in early age-related macular degeneration: preliminary findings from the Blue Mountains Eye Study. Clinical \& experimental ophthalmology 2006;34:590-595.

11. Klein R, Blodi BA, Meuer SM, Myers CE, Chew EY, Klein BE. The prevalence of macular telangiectasia type 2 in the Beaver Dam eye study. American journal of ophthalmology 2010;150:55-62 e52.

12. Gass JD, Blodi BA. Idiopathic juxtafoveolar retinal telangiectasis. Update of classification and followup study. Ophthalmology 1993;100:1536-1546.

13. Gillies $M C$, Zhu $M$, Chew $E$, et al. Familial asymptomatic macular telangiectasia type 2 . Ophthalmology 2009;116:2422-2429.

14. Adamus G, Ren G, Weleber RG. Autoantibodies against retinal proteins in paraneoplastic and autoimmune retinopathy. BMC ophthalmology 2004;4:5.

15. Cherepanoff S, Killingsworth MC, Zhu M, et al. Ultrastructural and clinical evidence of subretinal debris accumulation in type 2 macular telangiectasia. The British journal of ophthalmology 2012;96:14041409.

16. Brown AM, Sickmann HM, Fosgerau K, et al. Astrocyte glycogen metabolism is required for neural activity during aglycemia or intense stimulation in mouse white matter. Journal of neuroscience research 2005;79:74-80.

17. Okajima TI, Pepperberg DR, Ripps H, Wiggert B, Chader GJ. Interphotoreceptor retinoid-binding protein: role in delivery of retinol to the pigment epithelium. Experimental eye research 1989;49:629-644.

18. Hemmer W, Riesinger I, Wallimann T, Eppenberger HM, Quest AF. Brain-type creatine kinase in photoreceptor cell outer segments: role of a phosphocreatine circuit in outer segment energy metabolism and phototransduction. Journal of cell science 1993;106 ( Pt 2):671-683.

19. Gonzalez-Fernandez F. Interphotoreceptor retinoid-binding protein--an old gene for new eyes. Vision research 2003;43:3021-3036.

20. Bao Y, Dawson TL, Jr., Chen YT. Human glycogen debranching enzyme gene (AGL): complete structural organization and characterization of the 5 ' flanking region. Genomics 1996;38:155-165.

21. Dringen R, Gebhardt R, Hamprecht B. Glycogen in astrocytes: possible function as lactate supply for neighboring cells. Brain research 1993;623:208-214.

22. Tsacopoulos M, Magistretti PJ. Metabolic coupling between glia and neurons. The Journal of neuroscience : the official journal of the Society for Neuroscience 1996;16:877-885.

23. Len AC, Powner MB, Zhu L, et al. Pilot application of iTRAQ to the retinal disease Macular Telangiectasia. Journal of proteome research 2012;11:537-553. 
24. Mata NL, Weng J, Travis GH. Biosynthesis of a major lipofuscin fluorophore in mice and humans with ABCR-mediated retinal and macular degeneration. Proceedings of the National Academy of Sciences of the United States of America 2000;97:7154-7159.

25. Schmitz-Valckenberg S, Bultmann S, Dreyhaupt J, Bindewald A, Holz FG, Rohrschneider K. Fundus autofluorescence and fundus perimetry in the junctional zone of geographic atrophy in patients with agerelated macular degeneration. Investigative ophthalmology \& visual science 2004;45:4470-4476.

26. Scholl HP, Bellmann C, Dandekar SS, Bird AC, Fitzke FW. Photopic and scotopic fine matrix mapping of retinal areas of increased fundus autofluorescence in patients with age-related maculopathy. Investigative ophthalmology \& visual science 2004;45:574-583.

27. Wong WT, Forooghian F, Majumdar Z, Bonner RF, Cunningham D, Chew EY. Fundus autofluorescence in type 2 idiopathic macular telangiectasia: correlation with optical coherence tomography and microperimetry. American journal of ophthalmology 2009;148:573-583.

28. Okunuki Y, Usui Y, Kezuka T, et al. Proteomic surveillance of retinal autoantigens in endogenous uveitis: implication of esterase $D$ and brain-type creatine kinase as novel autoantigens. Molecular vision 2008;14:1094-1104.

29. Ahn BY, Song ES, Cho YJ, Kwon OW, Kim JK, Lee NG. Identification of an anti-aldolase autoantibody as a diagnostic marker for diabetic retinopathy by immunoproteomic analysis. Proteomics 2006;6:12001209.

30. Arawaka S, Daimon M, Sasaki H, Suzuki JI, Kato T. A novel autoantibody in paraneoplastic sensorydominant neuropathy reacts with brain-type creatine kinase. International journal of molecular medicine 1998;1:597-600.

31. Morohoshi K, Goodwin AM, Ohbayashi M, Ono SJ. Autoimmunity in retinal degeneration: autoimmune retinopathy and age-related macular degeneration. Journal of autoimmunity 2009;33:247-254. 32. Aloisi F. Immune function of microglia. Glia 2001;36:165-179. 
Table 1. Patient information and autoantibodies present ratio.

\begin{tabular}{|c|c|c|c|c|c|c|}
\hline & $\begin{array}{c}\text { Number of } \\
\text { participants }\end{array}$ & $\begin{array}{c}\text { Mean age } \\
\text { (years) }\end{array}$ & $\begin{array}{c}\text { Age range } \\
\text { (years) }\end{array}$ & $\begin{array}{c}\text { Sex } \\
(\mathrm{M} / \mathrm{F})\end{array}$ & $\begin{array}{c}\text { Diabetes/ } \\
\text { Non } \\
\text { Diabetes }\end{array}$ & $\begin{array}{c}\text { Autoantibodies } \\
\text { present, n (\%) }\end{array}$ \\
\hline Control & 58 & 45 & $21-78$ & $28 / 30$ & $13 / 45$ & $9(15.5 \%)$ \\
\hline Mactel & 45 & 59 & $37-79$ & $18 / 27$ & $11 / 34$ & $31(68.9 \%)$ \\
\hline
\end{tabular}

Table 2. Detail information of MS/MS identified target antigens.

\begin{tabular}{|c|c|c|c|c|c|c|c|}
\hline Target Peptide & Protein Name & OS & Mass & Protein Score & Matches & sequences & emPAI \\
\hline $\mathrm{X}$ & Glycogen debranching enzyme & Homo spiens & 174652 & 301 & $17(8)$ & $17(8)$ & 0.28 \\
\hline $\mathrm{Y}$ & Retinol-binding protein 3 & Homo spiens & 135278 & 2746 & $83(61)$ & $45(43)$ & 2.84 \\
\hline Z & Creatine kinase B-type & Homo spiens & 42617 & 8314 & $164(153)$ & $27(27)$ & 25.72 \\
\hline
\end{tabular}

Table 3. Immunohistochemistry in human retinas using MacTel-2 sera as primary antibodies and confirmation of the results using commercial antibodies.

\begin{tabular}{|l|l|l|}
\hline \multicolumn{1}{|c|}{ Protein Name } & Cellular Localization in the Human Retina & \multicolumn{1}{c|}{ Function } \\
\hline AGL & $\begin{array}{l}\text { strong staining around inner retinal vessels, } \\
\text { weak staining in astrocytes and cells in the } \\
\text { inner nuclear layer and outer nuclear layer }\end{array}$ & Glycogen metabolism, facilitating glycogen breakdown \\
\hline RBP3 & Photoreceptor outer segments & $\begin{array}{l}\text { Visual cycle trafficking, responsible for transfer of 11- } \\
\text { cis retinal and all trans retinol between photoreceptors } \\
\text { and retinal pigment epithelium }\end{array}$ \\
\hline CK-B & $\begin{array}{l}\text { Globally expressed throughout the entire retina } \\
\text { and high expression was observed in the } \\
\text { photoreceptor outer segments }\end{array}$ & $\begin{array}{l}\text { Energy metabolism, providing energy for the visual } \\
\text { cycle }\end{array}$ \\
\hline
\end{tabular}

\section{Figure Legends}

Figure 1. Retinal autoantibody detection by Western Blot. A. Total human retinal protein blotted with individual MacTel-2 patient's serum or control human serum. Bands indicate different retinal autoantibodies in MacTel-2 sera. B. Three different sizes of bands were detected by Western Blot. Antigen X ( 150 kDa), Antigen Y $(\sim 120 \mathrm{kDa})$ and Antigen $\mathrm{Z}(\sim 40 \mathrm{kDa})$ were frequently observed in MacTel-2 sera (asterisks) but not present in healthy controls.

Figure 2. Fractionation and separation of target antigen. A-C. Chromatographic separation of antigen $\mathrm{X}, \mathrm{Y}$ and $\mathrm{Z}$ from total human retinal proteins identified by autoantibody detection through 
Western blot. Asterisks indicate fractions containing target antigens. D-F. SDS PAGE further separated the target antigens. Asterisks indicate the target bands cut out for MS.

Figure 3. Immunohistochemistry in human retinae using MacTel-2 sera containing different autoantibodies identified by chromatographic fractionation and tandem mass spectrometry. Healthy subject serum was used as a control. Sections were also stained with propidium iodide (PI) for nuclear counterstaining. . A-C. MacTel-2 serum containing anti-AGL autoantibody. D-F. MacTel-2 serum containing anti-RBP3 autoantibody. G-I. MacTel-2 serum containing anti- CK-B autoantibody. J-L. Healthy subject serum without autoantibody. GCL: Ganglion cell layer, INL: inner nuclear layer, ONL: out nuclear layer. Scale bars: $60 \mu \mathrm{m}$.

Figure 4. Immunohistochemistry using commercial antibodies against AGL (A-C), RBP3 (D-F) and CK-B (G-I). Sections were also stained with propidium iodide (PI) for nuclear counterstaining. GCL: Ganglion cell layer, INL: inner nuclear layer, ONL: out nuclear layer. Scale bars: $60 \mu \mathrm{m}$.

\section{Supplementary material}

\section{Supplementary Figure 1.}

Recombinant human Creatine Kinase B-type protein (Abcam, ab73647) blotted with individual MacTel-2 patient's serum with putative CK-B autoantibody $(Z)$ or control healthy human serum (C). Bands indicate CK-B autoantibody in serum.

Details of LC-MS/MS results for three antigens identification.

AGL_Mascot.pdf

RBP3_Mascot.pdf

CKB_Mascot.pdf 


\section{Control human serum}

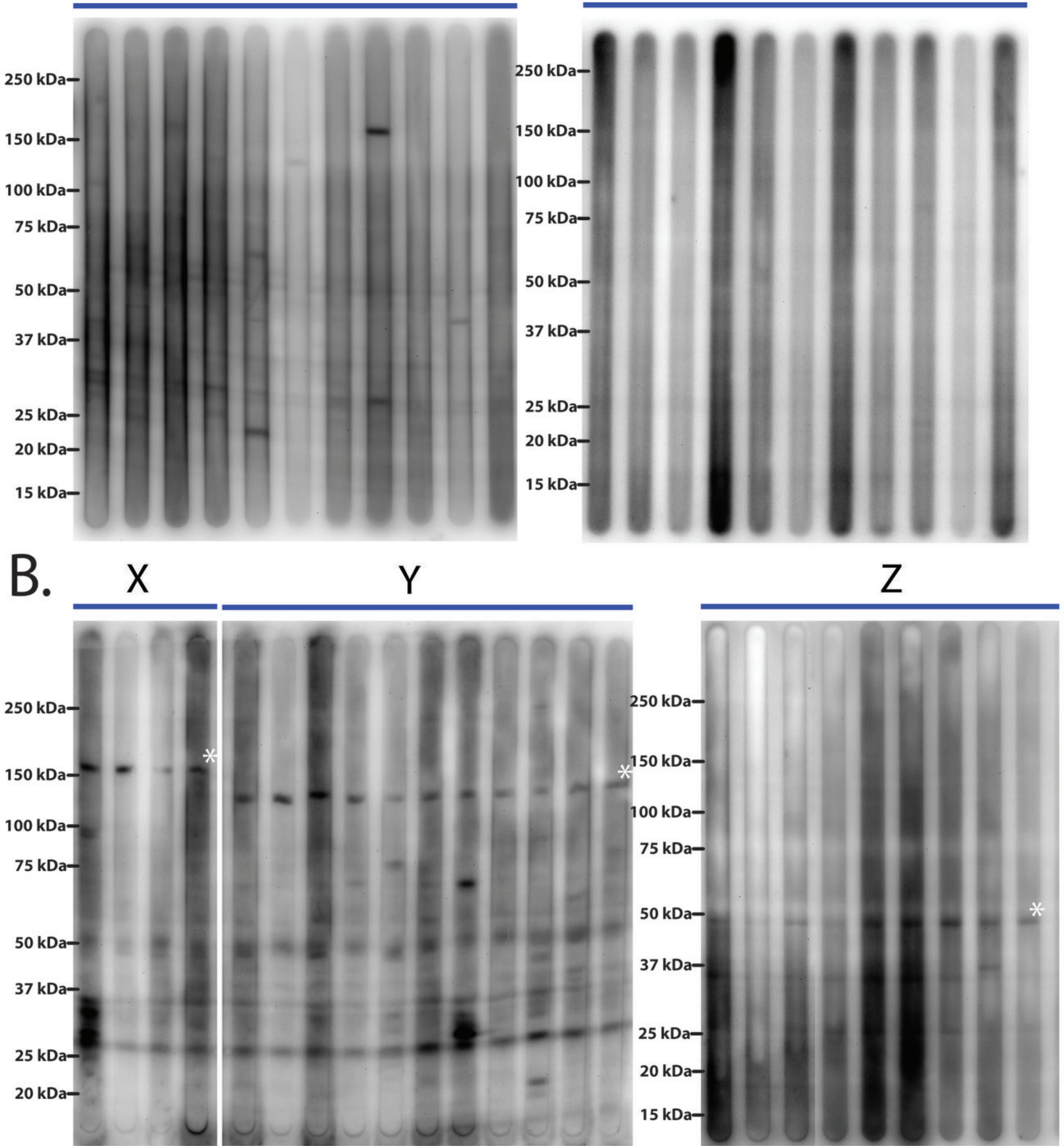




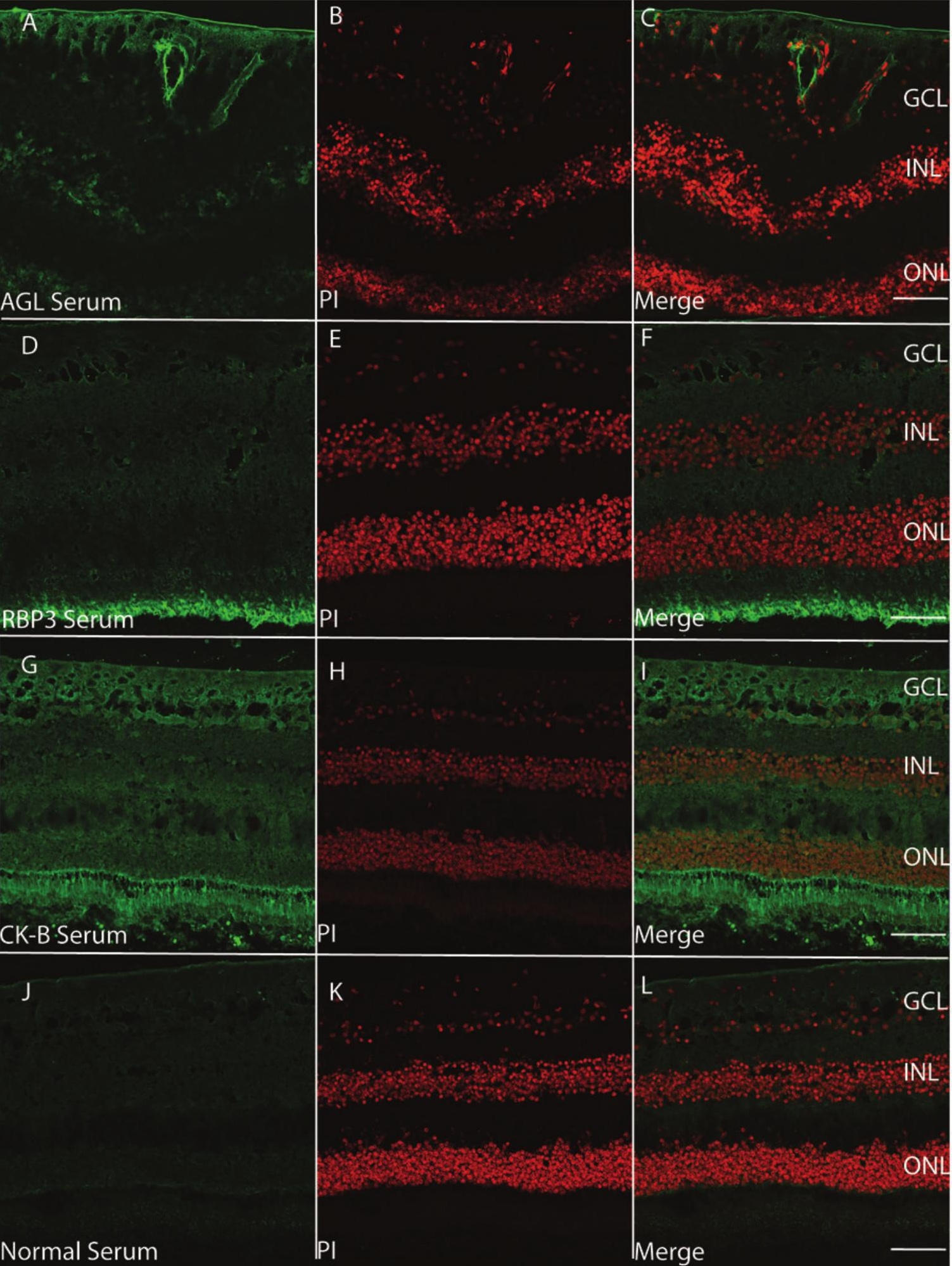




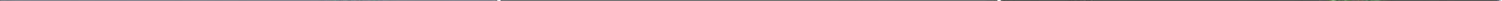

